\title{
A Sociocultural View of Language Learning: The Importance of Meaning-Based Instruction
}

\section{Barohny Eun and Hye-Soon Lim}

\begin{abstract}
The process of second-language teaching is grounded in the sociocultural theory of Vygotsky, which emphasizes meaningful interaction among individuals as the greatest motivating force in human development and learning. In this theoretical framework, the concepts of meaning and mediation are considered as the two essential elements affecting an individual's learning of a second language. Suggestions are offered for enhancing students' second-language learning in their regular classrooms by applying sociocultural theories to practice. Socioculturally based implications for classroom teaching include bilingual instruction, focus on pragmatics, literacy instruction based on drama, inclusive learning environments, instruction based on children's interests, and the teacher's role as a facilitator mediating between students and their second-language learning environment.
\end{abstract}

Le processus de l'enseignement d'une langue seconde repose sur la théorie socioculturelle de Vygotsky, qui maintient que l'interaction significative entre les personnes constitue l'impératif le plus important dans le développement et l'apprentissage des êtres humains. Dans ce cadre théorique, les concepts de signification et de médiation sont considérés comme les deux éléments essentiels affectant l'apprentissage d'une langue seconde. Nous proposons des façons d'appliquer les théories socioculturelles à la pratique pour améliorer l'apprentissage d'une langue seconde en salle de classe régulière. Parmi les implications socioculturelles pour l'enseignement, notons l'instruction bilingue, une concentration sur la pragmatique, l'enseignement de la littératie par l'art dramatique, des milieux d'apprentissage inclusifs, une pédagogie reposant sur les intérêts des enfants et le rôle de l'enseignant comme médiateur entre les élèves et leur milieu d'apprentissage d'une langue seconde.

\section{Introduction}

As many works on educating second-language or language-minority children have testified (Ariza, Morales-Jones, Yahya, \& Zainuddin, 2002; Leyba, 1994; Samway \& Mckeon, 1999; Scarcella, 1990), today's Canadian and United States classrooms are characterized by ever-increasing diversity both linguistically and culturally. McLaughlin (1994) argued that today's students are fundamentally different from those of yesterday in terms of the cultural 
perspectives, languages, family circumstances, values, and mores that they bring to their classrooms. These conditions create unprecedented demands for teachers to develop new knowledge and skills (Smylie \& Conyers, 1991) to meet the new challenges.

In the current classroom context, one of the greatest challenges facing teachers is that of instructing students who are acquiring English as a second language (ESL). Although these students frequently receive various types of additional language-instruction support outside their regular classrooms, most of their instructional time is spent in the regular classroom with a teacher who may or may not be familiar with their native language and culture.

Many approaches and instructional methods have been created and proposed with this specific challenge in mind. Diverse methods and techniques aimed at promoting language learning and acquisition have had their roots in various theories and traditions of general human development, with resultant advantages and disadvantages. For example, a strictly behavioristic interpretation of language acquisition has led to language-teaching methods such as the audiolingual method, which emphasizes such practices as rote memorization and language drills. On the other hand, cognitivist perspectives such as the language acquisition theories of Chomsky (1959) and Krashen $(1981,1982)$ have led to methodologies of language teaching that emphasize the learner's inherent ability to acquire language(s). The Natural Approach (Terrell, 1977, 1982) is an example of a language teaching method specifically developed on the basis of Krashen's theories of second-language acquisition. Finally, there is a theoretical perspective that emphasizes the importance of context in language learning, engendering approaches that have been termed sociocultural perspectives (Lantolf \& Thorne, 2006; Mitchell $\&$ Miles, 2004), which emphasize the integrated nature of individual (psychological) and social (environmental) elements in the learning process.

Much literature includes both theoretical and empirical studies inspired by sociocultural perspectives on second-language learning (Lantolf, 2000; Lantolf \& Appel, 1994; Lantolf \& Thorne, 2006). The purpose of this article is to build on the existing literature by focusing on the sociocultural theoretical framework-with its emphasis on contextual language learning-and to suggest concrete instructional implications for second-language teaching based on this framework. Following a brief introduction is an overview of the general theory of human development stemming from the sociocultural theories of Vygotsky, whose work has had an immense effect on all areas of education including language instruction. Explicating a general theoretical framework related to human development is important because languageteaching methodologies are created on the basis of theoretical perspectives, and language acquisition is a critical component of overall human development. Following an overview of the sociocultural theory, implications for 
second-language teaching are offered based on the fundamental tenets of the theory.

Before turning to the theoretical discussion, a note on terminology is in order. This article does not distinguish between the terms second-language acquisition and second-language learning. Although strictly speaking these two linguistic processes are differentiated-acquisition typically refers to the natural picking up of a second language through exposure, and learning refers to the conscious study of a second language (Ellis, 1985)—our discussion does not maintain such a distinction because the focus is on regular classrooms that include students for whom English is a second language. Thus the acquisition and learning processes for these students is so integrated and interdependent in the context of classroom instruction that separating them would be almost impossible and in a sense meaningless.

\section{Overview of Vygotsky's Sociocultural Theory}

As Kozulin (1990) noted, at the heart of Vygotsky's theory is a quest for identifying what is uniquely human about human development. Among the many concepts identified in this line of inquiry, the two most central notions - and those most closely related to linguistic processes-seem to be mediation and meaning. The theoretical overview in this section, therefore, focuses on these two key concepts.

\section{Mediation}

Through the concept of mediation, Vygotsky was able to answer the complex question of how human development occurs. Mediation refers to the process by which socially meaningful activities transform impulsive, unmediated, and natural behavior into higher mental processes through the use of instruments or tools (Minick, 1987). For example, in the process of development, children's direct (unmediated) memory develops into mediated memory (i.e., remembering by means of language or other signs). In one of his experimental studies, Vygotsky (1987) was able to demonstrate that children who initially quite poorly remembered a list of words were able to perform well when they were able to use picture cards to mediate their remembering process. Furthermore, these mediational means became internalized as development progressed so that in further stages of memory development, picture cards did not have to be physically present. Adolescents and adults were able to picture images mentally and associate them with the words to be remembered.

In elaborating the concept of mediation, Kozulin $(1990,2003)$ identified three major categories: mediation through material tools (e.g., using picture cards to aid remembering); mediation through symbolic systems (e.g., silently rehearsing the words to be remembered); and mediation through another human being (e.g., children could be supported by an adult in the process of 
remembering). Among these three categories it is well known that Vygotsky paid particular attention to symbolic mediators ranging from simple signs to literary works.

\section{Meaning}

Just as he identified mediation as the distinguishing characteristic of highly developed forms of human behavior, Vygotsky found that the distinctive and unique character of human speech was that it carried generalized meaning. Meaningful speech is contrasted with other types of speech that are found in the animal world as well as in human infants such as emotional expressions that are devoid of any generalized meaning. Meaning in this context is to be understood in terms of the degree of generalization and objectivity, namely, meanings that allow social communication to become possible across contexts (Vygotsky, 1987). One of Vygotsky's examples related to communicating to others that one is cold. This can be done in many ways including the simple gesture of shivering. In fact, animals and even infants frequently communicate with one another in such indicative gestures. However, these do not convey generalized meanings (i.e., objective meanings that are not bounded by contextual variability). In this sense written texts (i.e., written forms of communication) were deemed by Vygotsky to carry the most generalized meanings.

Humans develop the ability to acquire meaningful speech in their interaction with others. For example, in their interactions with adults, children continually ask the names of things (Vygotsky, 1987). At first, the name thus learned stands only for that specific object encountered in certain settings (i.e., not yet generalized). The word chair will refer only to a chair that the child has encountered in his or her dining room and not to other chairs. Later, in continuing communicative interactions with adults in various settings, children become able to generalize the word. So the word chair not only stands for the specific chairs that the child has seen, but to all objects that meet the definition of chair regardless of the child's direct experience with the object. Thus the word chair achieves a signifying function and attains generalized meaning.

Vygotsky's emphasis on the importance of meaning may also be well illustrated through his discussions of various types and modes of speech. Whether the mode of speech was sign language or another specialized form of speech, the matter of critical importance to Vygotsky was the need to retain meaning. In the context of outlining the course of development for students who were blind, deaf, or mute, Vygotsky maintained that modified educational methods as well as alternative symbolic systems were required to facilitate development. However, although sign systems might be altered and modified, it was critical that meaning be retained. Vygotsky's (1924) 
basic claim was, "Meaning rather than a sign is important. Let us change signs but retain meaning" (p. 54, quoted in Kozulin, 1990, p. 201).

\section{Mediation by Language and Interpretation Based on Meaning}

Vygotsky's developmental theory emphasizes mediation and meaning because the mechanism underlying development, including linguistic development, occurs through social interaction. Development is made possible and fostered by meaningful exchanges between people (John-Steiner, Panofsky, \& Smith, 1994). In the initial stages of language acquisition, people first focus on the meaning of words and only later focus on the forms. Mutual understanding of the meaning contained in the speech of interlocutors is what makes linguistic development possible.

As can be seen from the above discussion, the developmental process in the Vygotskian perspective is always initiated between people (i.e., the intermental plane) and only gradually moves into the individual's psychological plane (i.e., the intramental plane). In other words, people develop through interactions with others that are conducted primarily by means of the linguistic system. In this process people internalize the forms of behavior and language used between individuals. This internalization is guided by the process of linguistic mediation. In addition to the symbolic mediator (i.e., language), human mediators play significant roles because social interaction involving two or more people provides the basis for internalization and consequently development.

The fact that human behavior is mediated by language gives rise to the phenomenon that all human action is subject to multiple interpretations (Vygotsky, 1987). This is why Vygotsky was preoccupied with semanticlevel analyses as well as being fascinated with the theatrical techniques and stage directions that gave emphasis to interpreting and expressing multiple meanings inherent in the speech of actors (Kozulin, 1990).

\section{Implications for Second-Language Teaching}

From the above overview of Vygotsky's theoretical framework, it is evident that meaning and mediation serve as the two main threads that interweave all the basic principles of Vygotsky's theory. In this section these two concepts serve as a bridge that links Vygotsky's theoretical underpinnings with the realm of classroom practice where the actual language teaching and learning process occurs every day: meaning-based instruction and the importance of human mediators.

\section{Meaning-Based Instruction}

Bilingual instruction. It would not be an exaggeration to state that bilingual instruction is one of the most debated areas in the field of education. Numerous pros and cons stem from both theoretical and empirical grounds 
(Samway \& McKeon, 1999). As the goal of this article is to present instructional implications based on the theories of Vygotsky, the issue of bilingual instruction as well as the following implications are explored in this theoretical context.

Considering Vygotsky's claim about the relationship between sign and meaning, it becomes clear that he was taking the side of those asserting that "language and academic development is better approached through a respect for, and incorporation of, a student's primary language" (Díaz-Rico $\&$ Weed, 2002, p. 2). In the context of discussing alternative means of educating students who were blind, deaf, or mute, Vygotsky (1997) consistently emphasized the importance of retaining meaning and only changing the sign system. In this view, cognitive and linguistic development is possible only when the meaning contained in the sign system is interpreted by the individual. In other words, it makes no difference whether a deaf person understands the meaning of others' speech by lipreading, or a non-hearingimpaired person uses his or her hearing to understand what others mean through the spoken word. This line of reasoning supports using students' L1 to help them understand the content matter of subjects because this would significantly enhance their cognitive development.

In Thinking and Speech (1987), Vygotsky provided one of the clearest arguments for bilingual instruction. He specifically noted that the learning of an L2 had its foundation in the knowledge of one's L1. Furthermore, he argued that the semantic aspects of a word were acquired before the actual name of the word. This means that learning an L2 ultimately depends on the developed semantic system of the L1. One learns conceptually first by depending on one's L1 and masters the actual name of the word in an L2 only later. For example, explaining a mathematical theorem (i.e., a concept) does not necessarily have to occur in the second language that the students are learning. Rather, providing the content (i.e., the meaningful aspect of the concept) in the students' L1 would be a more productive instructional approach. The specific words that designate certain mathematical theorems could be acquired later in the second language. Finally, learning or knowing two languages influences the developmental processes of each language, which means that by simultaneously being exposed to two languages, one gains a deeper and broader understanding of both languages.

Focusing on pragmatics. Discussing the progression of Vygotsky's ideas about the development of speech, Minick (1987) noted that Vygotsky was particularly aware of the fact that in speech, forms do not usually map directly into one meaning. Both lexically and grammatically, polysemy (multiple meanings) prevails: because of this nature of the relationship between form and meaning, Vygotksy emphasized the importance of pragmatic competence in language development. 
Pragmatics refers to the area of linguistics mainly concerned with determining the meaning of language in context. In addition to mastering the lexicon and grammar of a language, one must know how and when to use certain forms appropriately to convey certain meanings under certain conditions. The acquisition of pragmatic competence can pose significant challenges for second-language learners, as this area of linguistic competence may differ significantly from what they know based on their L1. Therefore, aspects of speech that may come naturally for L1 speakers (e.g., intonation, certain idioms) might have to be explicitly explained to L2 learners.

For example, in some circumstances, correspondence may be lacking between psychological and grammatical subjects and predicates (Vygotsky, 1987). Vygotsky gave an example of a simple sentence to illustrate this point: The clock fell. When you see a clock that has stopped and ask What happened? and you receive the answer The clock fell, the psychological and grammatical subjects and predicates coincide. The clock is the subject and fell is the predicate in terms of both psychology and grammar. However, when you hear something crashing to the floor and then ask What fell? and you receive the answer The clock fell, the grammatical and psychological subjects and predicates do not coincide. In this latter case you know that something fell, and so your only interest is in the object that has fallen. Thus the answer might be better interpreted as What fell is the clock, in which case what fell becomes the psychological subject and the clock becomes the psychological predicate.

Lantolf and Thorne (2006) related the concepts of psychological subject and psychological predicate to topic-comment organization, the themerheme notion, and the pattern of given-new information. The former concepts in each of the pairs, that is, psychological subject, topic, theme, and given information, are known to the speaker and provide no new information. Thus in the above example, when someone asks What fell? with the knowledge that something has fallen, the part of the sentence that contains information about the fact that something has fallen is the psychological subject. However, the grammatical subject of the sentence The clock fell is the clock. Conversely, because the speaker does not know the object that has fallen, the clock becomes the psychological predicate, but grammatically it is the subject of the same sentence The clock fell. Where psychological and grammatical subjects and predicates do not coincide, a wide variety of meanings can reside in a single grammatical structure, and second-language learners may need explicit instruction in this domain to determine meaning fully from the context.

Based on this line of reasoning, Vygotsky (1987) also emphasized the importance of learning diverse speech modes and genres in the course of language acquisition. Precisely because in speech there is no one-to-one correspondence between form and meaning, the issue of when to use a certain form to convey a certain meaning becomes important. The appropri- 
ateness of speech modes and genres largely depends on the context and purposes of the interlocutors, and L2 learners often need explicit instruction in this area.

Literacy instruction based on techniques from drama. Strong arguments in favor of literacy instruction based on drama techniques come from various levels of the speech development analyses in Vygotsky's empirical and theoretical research. First, in a picture description experiment, Vygotsky (1987) was able to reveal an important point related to the relationship between action and verbal description about the meaningful aspect of speech. After being shown a single group of pictures, two groups of children were asked either to act out the events depicted in the picture or to explain them orally. The results of the study indicated that children could reproduce the content of the pictures better through action than through oral explanation.

On a more theoretical plane, Vygotsky (1987) distinguished two levels of speech. At one level is the spontaneous use of words, and at the other is conscious awareness of words. The former may be conceptualized as a lower, basic level and the latter as the higher, more complex level that builds on the foundation provided by the basic level. This makes sense, as Vygotsky consistently claimed that for one to be conscious of something, one first had to possess it.

In explaining the cause of difficulties that so many school-aged children experience in learning written speech, Vygotsky (1987) identified the main source as the dually abstracted character of written speech. That is, written speech requires an abstraction from the auditory aspects of speech (sound) as well as an abstraction from the interlocutor. When beginning literacy instruction, most children are not well equipped to deal with complex abstractedness. For L2 learners, whose oral speech may not be as well developed as that of their L1 peers, the transition to the written mode of speech may be a daunting task.

The context of language use becomes less abstract, fuller, and more saturated with meaning when written speech is transformed into oral speech, when acting out the actual events replaces relying on verbal description alone, and when sound, interlocutors, and a visible audience are provided, all of which enhance children's acquisition of written speech as they consciously become aware of the language contained in the drama.

As with all instructional methods, drama-based instruction has its limits because not all written texts lend themselves easily to the language of drama. Depending on the genre, some written texts may be resistant to transformation into drama. However, our main argument is that when written texts are carefully chosen, drama can serve as a good starting point for literacy instruction and development. 
The importance of inclusion. In all areas of education Vygotsky clearly favored the concept of inclusion. His objection to grouping children based on similarity - whether based on learning capability or severity of sensory challenge-was based on his belief that collective experience mediated the psychological development of the individual (Kozulin, 1990). This belief was not surprising given Vygotsky's consistent emphasis on the primacy of social development in human psychological processes: what is acquired in the process of interaction between people is later transformed into the inner processes of the individual.

For example, confining deaf learners to the world of the deaf (Kozulin, 1990) severely limits their development because this type of secluded environment significantly limits students' potential for interaction with the rest of the world. The goal of instruction in this case should not lie in providing a comfortable environment with limited possibilities for social interaction, but in providing opportunities for the individual to experience the most diverse types of human interaction possible. Only in this way will the learner be able to realize his or her full potential.

Based on Vygotsky's developmental theory, the practice of pull-out second-language instruction would serve to limit rather than enhance the process of second-language learning. When children are grouped according to their similarity with respect to second-language proficiency, opportunities for the most varied types of interaction are limited, which in turn has a negative effect on language development. Second-language acquisition studies delving into the role of deviant, that is, nonstandard, input have reached similar conclusions about the negative effects of similar ability/proficiency grouping of students (for a description of deviant input studies, see Larsen-Freeman \& Long, 1991).

Based on the above considerations, it may be concluded that children should spend most of each school day in the regular classroom where the most diverse types of social interaction are possible and realized. This in turn would mean that less time should be spent in pull-out ESL programs, contrary to the widely accepted practice among schools in much of North America. As mentioned above, the type of grouping typically encountered in pull-out ESL instruction limits possibilities for the various types of social interaction that would be available in regular classrooms. In addition, the types of language input to which second-language learners are exposed in pull-out ESL classrooms may serve to hinder rather than advance their second-language development.

Instruction based on children's interests. Vygotsky (1997) viewed instruction based on children's interests and needs as one of the most fundamental principles of education. Furthermore, according to Vygotsky, the only type of instruction that may arouse students' interest is instruction that is meaningful to the students themselves. More specifically, this points to what is 
relevant, purposeful, and has personal significance in the lives of the children.

One of the best ways to structure instruction in a form that is meaningful for learners is to connect it to their real lives in the real world. Second-language learners who live in an environment that continually reinforces the use of the language that they are learning will already know the value and importance of the target language. However, if the forms and functions of language that they are learning in school are far removed from those acquired outside the school, they may begin to question the relevance and purpose of school instruction. At the beginning level, for example, language instruction should be aimed toward fulfilling the students' basic interpersonal communication needs.

As students continue their formal schooling-or with students who are more advanced or in higher grades-it becomes important to consider the relevance of language-learning to academic subjects in addition to real-life usage. Content-based instruction (CBI) is a language-teaching methodology based on relating language-learning to content-learning. Although most often CBI is based on content from academic subject matter, researchers like Genesee (1994) have suggested that the content in question need not be academic, but can include any topic, theme, or nonlanguage issue of interest or importance to the learners. The critical issue is to focus on content that is based on students' interests and needs so that it is meaningful in their lives.

\section{The Importance of Human Mediators}

As Kozulin (1990) noted, one of the primary instruments of mental development, including linguistic development, is meaning, and meaning in turn depends primarily on interpersonal semiotic (verbal) interaction. This is also in accord with the general law of development as espoused by Vygotsky, 1978, 1987), which he called the general law of cultural development. This law states that all higher mental functions develop from the outside-or from the intermental plane to the intramental plane-through the mechanism of mediation. In the context of second-language learning, this would imply that children develop their second-language proficiency by interacting with other people in the target language, with these forms of social interaction becoming gradually internalized, thus inducing language development. The student becomes independently able to use forms and functions of language that can be employed only in the context of oral interactions with other people.

However, not all types of oral interaction have equal potential to enhance the second-language development process. As Kozulin (2003) observed, not all adult-child interactions produce mediational effects in instructional situations. Important factors that contribute to the process of language development include the people engaging in the interactions, as well as the setting 
where the interactions occur. In this section, the focus is on the people with whom second-language learners engage in social interactions, or the individuals who play the role of human mediators in the process of linguistic development (Kozulin, 1990, 2003). More specifically, the focus is on the role of the adult, that is, the teacher, in playing the role of mediator. Although peer interactions are important, the focus of this discussion aims to provide theoretically derived teaching implications.

A crucial consideration is how the process of mediation has both universal features and culture-specific characteristics. With this in mind, teachers should reflect on potential differences between mediational processes that exist in their students' cultural backgrounds and those found in the schools (Kozulin, 2003). The first step in this process would be for teachers to learn as much as possible about the dominant mediational patterns of their students' cultures. In some instances teachers' respect for the cultural mediational patterns of their students has been shown to lead to optimal learning situations. For example, Collignon (1994) reported a study where the teacher's respect for Hmong women's cultural styles of learning supported the development of the target language for these women.

In addition, as Vygotsky (1997) emphasized many times, the best-or the only possible-role that the teacher can play in the dynamic process of teaching and learning is that of the "director of the social environment" (p. 339). That is, the only way a teacher can influence a student's learning process is by changing the instructional environment. Vygotsky used the metaphor of a gardener to illustrate his points: just as gardeners would not directly attempt to affect the growth of their plants by tugging at the roots from underground, teachers should not attempt directly to influence the educational process by transmitting knowledge to their students. Just as a gardener would rather direct efforts at changing the conditions of plant growth by increasing the temperature, regulating the moisture, and choosing the right type of fertilizer, the teacher should focus on changing the social environment of the classroom by introducing appropriate activities and creating challenging problem-solving situations.

In outlining the role of social interaction, Vygotsky (1987) argued that verbal interaction with adults was the strongest motivating force underlying children's cognitive development. Language development will be more responsive to the influence of interactions with adults when this interaction is predominantly oral. Various suggestions for enhancing teacher-student interactions, both oral and written, have been offered in the second-language acquisition literature (e.g., reading-group discussions across the content areas, and dialogue journals), and we do not repeat this familiar material here. Our purpose is rather to a provide theoretical rationale as to why and how these types of interactions work to influence the process of language development among second-language learners. 


\section{Conclusions}

The purpose of this article is to ground second-language learning in the general developmental theoretical framework provided by Vygotsky and to propose concrete instructional methods that can be recommended on the basis of this theoretical framework. The fundamental thesis of the sociocultural view of human development is that development proceeds from outside to within, or from the intermental to the intramental plane. What students initially acquire as a function of interaction between people is later internalized as individual functions. The concept of mediation underlies the transference from the social to the individual, from basic functions to higher and more complex functions, or more specifically, the mechanism of development itself relies on the concept of mediation. Mediation in turn is defined in relation to the meaningful aspect of speech.

Specifically because all higher mental processes including the learning of a second language are mediated by the meaningful aspect of language, it becomes essential for second-language teaching to focus on the meaningfulness of speech. Because concepts should be developed first, and the names of the words that designate them later, and because second-language learners already possess a meaningful linguistic system in their first language, second-language teaching should initially rely on the learners' L1 to provide the concepts of the second language. Similarly, because concepts and conversational skills evolve before the development of literacy skills, literacy instruction should make use of the techniques of drama, which can build on the foundation of the developed conceptual system and of oral language proficiency.

As there is a lack of one-to-one correspondence between meaning and linguistic form, second-language learners should be explicitly taught the pragmatics of the second language. Also, the best way to achieve proficiency in all aspects of language use is by being exposed to the most varied types of social verbal interactions possible; so including second-language students in the regular classroom rather than in pull-out second-language classrooms should provide the optimal social environment for acquiring a new language. Of course, this presupposes that the classroom will provide rich input in both print and oral forms. Teachers' involvement is critical in this context because the task of creating optimal conditions for enhancing languagelearning ultimately falls on them. Finally, as with instruction in any subject matter, second-language learning should be based on children's own interests, needs, and purposes. Connecting language instruction to the real world or to various academic subjects is one way to implement this principle.

\section{The Authors}

Barohny Eun graduated from the University of North Carolina at Chapel Hill with a doctorate in education with an emphasis on teaching English as a second language. 
Hye-Soon Lim is a professor in the Department of English Language and Literature at Hallym University in Korea. His main research interests include sociolinguistics, English education theory, and the history of the English language.

\section{References}

Ariza, E.N., Morales-Jones, C.A., Yahya, N., \& Zainuddin, H. (2002). Why TESOL? Theories and issues in teaching English as a second language for K-12 teachers (2nd ed.). Dubuque, IA: Kendall/Hunt.

Chomsky, N. (1959). Review of the book Verbal behavior. Language, 35, 26-58.

Collignon, F.F. (1994). From "Paj Ntaub" to paragraphs: Perspectives on Hmong processes of composing. In V. John-Steiner, C.P. Panofsky, \& L.W. Smith (Eds.), Sociocultural approaches to language and literacy: An interactionist approach (pp. 331-346). Cambridge, UK: Cambridge University Press.

Díaz-Rico, L.T., \& Weed, K.Z. (2002). The crosscultural, language, and academic development: A complete K-12 reference guide (2nd ed.). Boston, MA: Allyn and Bacon.

Ellis, R. (1985). Understanding second language acquisition. Oxford, UK: Oxford University Press.

Genesee, F. (1994). Integrating language and content: Lessons from immersion. Educational Practice Report 11. National Center for Research on Cultural Diversity and Second Language Learning.

John-Steiner, V., Panofsky, C., \& Smith, L.W. (1994). Introduction. In V. John-Steiner, C. Panofsky, \& L.W. Smith (Eds.), Sociocultural approaches to language and literacy: An interactionist perspective (pp. 1-33). Cambridge, UK: Cambridge University Press.

Kozulin, A. (1990). Vygotsky's psychology: A biography of ideas. Cambridge, MA: Harvard University Press.

Kozulin, A. (2003). Psychological tools and mediated learning. In A. Kozulin, B. Gindis, V.S. Ageyev, \& S.M. Miller (Eds.), Vygotsky's educational theory in cultural context (pp. 15-38). Cambridge, UK: Cambridge University Press.

Krashen, S. (1981). Second language acquisition and second language learning. Oxford, UK: Pergamon.

Krashen, S. (1982). Principles and practice in second language acquisition. Oxford, UK: Pergamon.

Lantolf, J.P. (Ed.). (2000). Sociocultural theory and second language learning. Oxford, UK: Oxford University Press.

Lantolf, J.P., \& Appel, G. (Eds.). (1994). Vygotskian approaches to second language research. Norwood, NJ: Ablex.

Lantolf, J.P., \& Thorne, S.L. (2006). Socio-cultural theory and the genesis of second language development. Oxford, UK: Oxford University Press.

Larsen-Freeman, D., \& Long, M.H. (1991). An introduction to second language acquisition research. New York: Longman.

Leyba, C.F. (1994). (Ed.). Schooling and language minority students: A theoretical framework (2nd ed.). Los Angeles, CA: University of California, Evaluation, Dissemination, and Assessment Center.

McLaughlin, M.W. (1994). Strategic sites for teachers' professional development. In P.P. Grimmett \& J. Neufeld (Eds.), Teacher development and the struggle for authenticity: Professional growth and restructuring in the context of change (pp. 31-51). New York: Teachers College Press.

Minick, N. (1987). The development of Vygotsky's thought: An introduction. In R. Rieber \& A. Carton (Eds.), The collected works of L.S. Vygotsky (N. Minick, Trans., vol. 1, pp. 17-36). New York: Plenum Press.

Mitchell, R., \& Myles, F. (2004). Second language learning theories. Oxford, UK: Oxford University Press.

Samway, K.D., \& McKeon, D. (1999). Myths and realities: Best practices for language minority students. Portsmouth, NH: Heinemann. 
Scarcella, R. (1990). Teaching language minority students in the multicultural classroom. Englewood Cliffs, NJ: Prentice-Hall.

Smylie, M.A., \& Conyers, J.G. (1991). Changing conceptions of teaching influence the future of staff development. Journal of Staff Development, 12, 12-16.

Vygotsky, L.S. (1924). Psikhologiya i pedagogika detskoi defektivnosti (Psychology and pedagogy of a child's disability). In L.S. Vygotsky, Collected papers, Vol. 5.

Vygotsky, L.S. (1978). Mind in society: The development of higher psychological processes (M. Cole, Ed.). Cambridge, MA: Harvard University Press.

Vygotsky, L.S. (1987). Thinking and speech. In R. Rieber \& A. Carton (Eds.), The collected works of L.S. Vygotsky (N. Minick, Trans.) (vol. 1, pp. 39-285). New York: Plenum Press.

Vygotsky, L.S. (1997). Educational psychology. Boca Raton, FL: St. Lucie Press. 